\title{
Materials for the 21 st century: What will we dream up next?
}

\begin{abstract}
Mark Miodownik
I look 50 years into the future of materials science to assess possible technological advances and their impacts on engineering, society, and culture. Themes such as cities, energy, food and drink, and healthcare are explored in terms of their materials requirements and our likelihood of fulfilling them. Possible directions for materials science and engineering are explored, such as metamaterials and technical textiles, along with their potential impacts on human expression in design, fashion, and architecture. As the number of available materials increases, I assess the likelihood that the methodology of materials development itself might evolve. Will experiments continue to dominate, or will approaches that combine big data and theory become more important forms of materials discovery? Or, more controversially, will our 10,000-year-old track record of materials innovation come to an end, as we run out of new materials to invent?
\end{abstract}

"The best way to predict the future is to create it."

\section{-Abraham Lincoln}

\section{Introduction}

If you are reading this article in the second half of the $21 \mathrm{st}$ century and are wondering how you came to live in a world where buildings harvest their own energy, bridges heal themselves, clothes monitor your health, and centenarians compete in a world tennis tournament, then I hope to explain the thinking that made your present a reality. Alternatively, if your world does not resemble this description, if you are in the grip of mass migrations, water shortages, and energy blackouts, then let me describe to you why an alternative future was a possibility in 2015. But first, I need to talk about why materials science and engineering are so influential in shaping civilizations.

The ancient Egyptians used glass only for decoration and ornamentation and could not have known that the material would provide the platform for the inventions of modern physics, chemistry, biology, and much more. Even the Romans, who were great innovators in glass and who invented the glass window, did not predict how important the material would be. It was the invention of the glass lens that turned out to be crucial for the birth of science, leading to the development of astrophysics and biology, through the development of the telescope and the microscope, respectively. ${ }^{1}$ Other innovations in glass had huge impacts, such as the development of borosilicate glass (e.g., Pyrex) and the test tube, without which the subject of chemistry would essentially not exist. In modern times, the glass optical fiber has revolutionized telecommunications and is the backbone of the Internet, which would grind to a halt without it. ${ }^{2}$

Glass is just one of many influential materials that have played decisive roles in our history. Materials are not just the stuff we make things from; they are expressions of our needs and desires. Reinforced concrete, for instance, is an expression not just of our need for shelter from the elements but also of our desire for infrastructure that is cheap enough to benefit all. Fifty percent of everything that gets made in 2015 will be made of concrete. ${ }^{3}$ It is, by weight, easily mankind's most popular material, underpinning all of our lives. Will we still be using it in 2050? Probably, because we will still need shelter and we will still want the creative architectural freedom the material provides, but it is likely to be a version that is more sustainable and heals itself. ${ }^{2}$

In this account of the trajectory of our material world from 2015 to 2050, I take as my compass human needs such as sustainable cities, energy security, food security, and health care, and I unpack the characteristics of the materials technologies and communities that will be key to achieving them. But there are other important influences too, such as aesthetics. 
Walk around many science and engineering departments in 2015 and you can easily convince yourself that there is no need for new fabrics now that jeans and t-shirts have been invented - but this would be to ignore the importance of fashion as a driver of materials technologies.

What makes us human is not just the physical materiality of our bodies; we are immaterial too and have interior and emotional lives. The material world, although separate, is not divorced from these worlds but rather strongly influences them, as anyone knows: Sitting on a couch affects our emotional state in a very different way than sitting on a metal stool. This is because, for humans, materials are not just functional; early archeological evidence shows that, as soon as we developed tools, we were also creating decorative jewelry, pigments, art, and clothing. The materials used for these purposes were developed for aesthetic and cultural reasons, and this has been a strong driver of materials technology throughout history (and has had unexpected impacts, as already mentioned for the example of glass). Because of this strong connection between materials and their social roles, the materials that we favor, the materials with which we surround ourselves, are significant to us: They mean something; they embody our ideals; they give us part of our identity. ${ }^{2}$

Designers and architects consciously use these meanings to create clothes, products, and buildings that we like, that we identify with, that we want to surround ourselves with. In this way, the meanings of materials are reinforced by our collective behavior. People buy clothes that reflect the type of person they want to be, or aspire to be, or are forced to be. Fashion designers are expert in these meanings. In every aspect of our lives, we choose materials that reflect our values: in our bathrooms, in our living rooms, in our bedrooms. But similarly, others impose their values on us in the workplace, in our cities, and in our airports. Authors, artists, photographers, and filmmakers imagine new futures, and in doing so, they change our views of both current and future technology. Thus, there is a constant reflection, absorption, and expression going on in the material world that remaps the meanings of materials around us.

This mapping, though, is not a one-way street: The desire for stronger, more comfortable, waterproof, breathable materials creates a need for the understanding of the internal material nanostructures and microstructures that are required to create them. This drives the scientific understanding and, so, drives materials science. In a very real way, then, materials science and engineering represent a reflection of our human dreams.

We live in the dream world of past generations, literally a world they imagined into existence through the materials technology they engineered. So what dream world will the materials engineers of 2015 bequeath to our children and grandchildren in 2050? (See Figure 1 for one artist's conception of such a world.) Will bionic people with synthetic organs, bones, and even brains become the norm? As we become more synthetic, will our human-made environment change to become more lifelike, so that living buildings and objects that heal themselves become the norm in 2050 ?

Another materials development trend that is likely to affect the materials pallet of the 21 st century is that of how we discover new materials. Our ancestors were experimentalists: Pretty much all of the major materials classes of fabrics, metals, ceramics, glasses, plastics, and composites were discovered through experiment, often by accident. They were not theoryled. The birth and progress of modern physics and chemistry and their application to materials science have allowed, for the first time in human history, the development of made-toorder materials designed atom by atom. Will this approach dominate materials discovery in 2050, or will experiments and accidents continue to provide our materials as they have in the past? The search for room-temperature superconductivity is a good example of such a potential discovery, which might yet be brought into being by the application of quantum mechanics. Will new methodological ideas being developed in 2015, such as the materials genome approach, ${ }^{4}$ turn out to be important drivers of innovation, or will we have to admit that the material world is too complex, and that biological organisms have it right by using an evolutionary mechanism. ${ }^{5}$

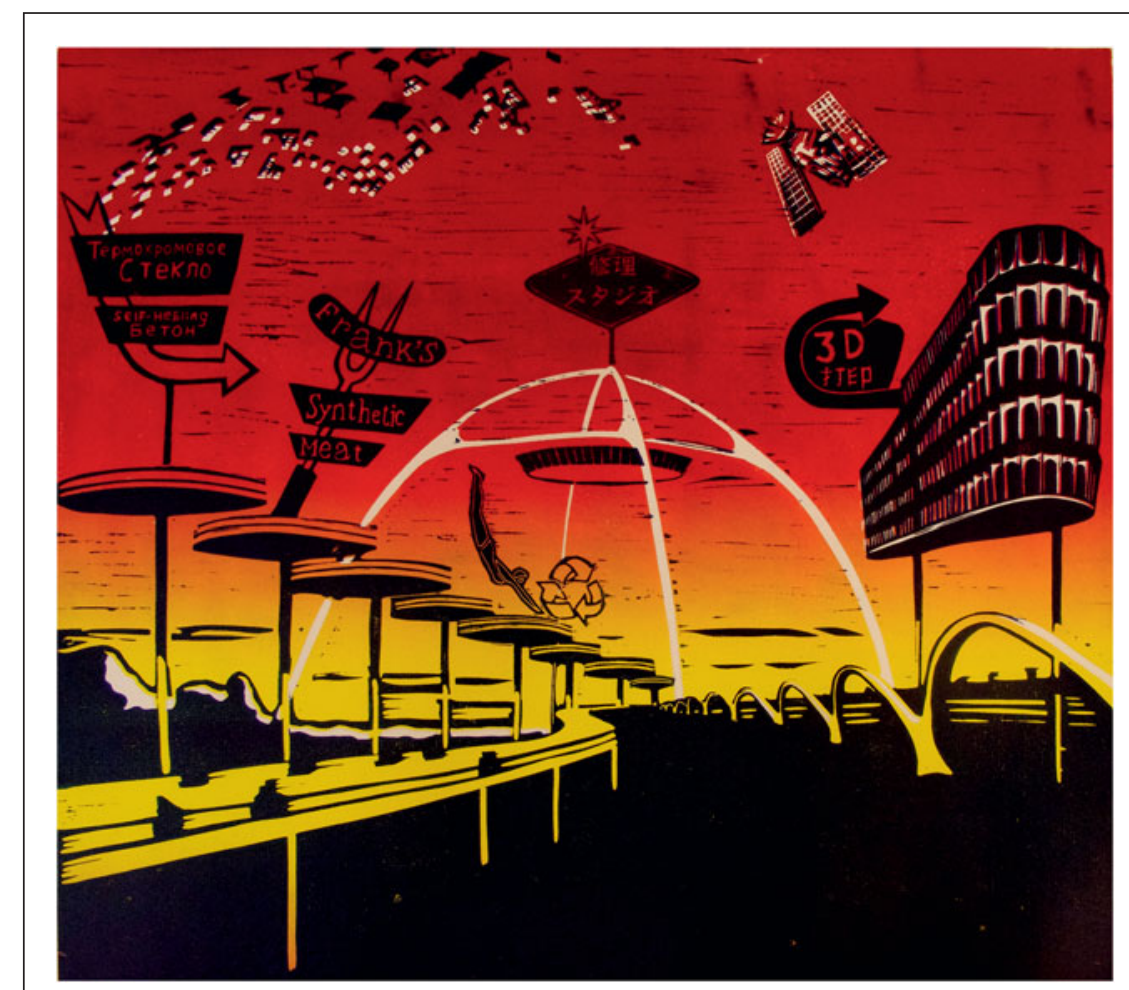

Figure 1. One of our possible futures: where buildings harvest their own energy and bridges heal themselves. 
This is important, because getting it right will be crucial for, among many pressing needs, averting the worst impacts of climate change for the residents of Earth in $2050 .^{6}$

\section{Materials needs}

A number of drivers of future materials needs in 2050 have been identified by analysts and policy makers from around the world, and in this article, I consider four of these: (1) sustainable cities, (2) energy security, (3) food and water security, and (4) health care.

\section{Sustainable cities}

A primary need of humans is for shelter and security, and satisfying this need in a sustainable way will require the growth of cities. The United Nations Department of Economic and Social Affairs estimates that, by $2050,66 \%$ of a world population of 10 billion will live in cities. ${ }^{7}$ Many issues arise when thinking about future cities, the first of which is whether we might run out of materials to build them.

Concrete, steel, and glass, currently the most important materials for construction, are derived from rocks and ores that are abundant in Earth's crust: There appears to be no danger of running out of them. ${ }^{8}$ Other materials required for city infrastructure, such as copper for electrical and electronics applications, tungsten for tools, and lithium for batteries, are neither plentiful nor geographically widely distributed throughout the world. Factors such as rarity, the geographical locations of ores, and the unpredictable impacts of political and economic factors can and will limit supply. ${ }^{8-11}$

A recent example is the restrictions placed by China on the export of rare-earth metals in $2010 .{ }^{12}$ The price of metals such as neodymium, which rapidly became economically important for the development of electric vehicles, increased, and supply for companies outside China was restricted. These types of occurrences have seen certain countries, such as the United States, reinstate lists of strategic materials that are deemed important for national security. ${ }^{13}$ As our material wealth becomes more complex in terms of its composition, so too does it become more vulnerable to supply uncertainty and price fluctuations.

Legislation is also becoming important. For example, Ashby ${ }^{8}$ showed that the restriction of materials because of their toxicity or because their extraction is deemed to contribute to conflict is rapidly increasing, in particular as a result of legislation designed to protect the environment and ecosystems. ${ }^{14}$ This affects many materials currently used for catalysts, such as platinum-group metals. For these reasons, it is highly likely that by 2050, a major theme of materials science will be the design of materials and engineering systems that minimize supply risks and environmental damage. Metamaterials, materials engineered to have properties that have not yet been found in nature, have the potential to be highly influential in this regard, because - as biological systems amply demonstratewith a few common ingredients, a wide range of materials properties can be generated. ${ }^{15}$
Polymers as a class of material will be especially vulnerable to supply risk. They account for a significant part of our infrastructure, in terms not of tonnage but of their critical role in, for example, water pipes, electrical insulation, paints, adhesives, and elastomers such as rubber tires. As of 2015, the feedstock for these materials is crude oil, which is not a renewable resource and which, at current rates of consumption, will run out in the 21 st century. ${ }^{11}$ Estimates of exactly when this will happen depend on assumptions about the continued use of oil for the production of gasoline, because, presently, only $4 \%$ of extracted crude oil is used for polymers; the rest is burned. Two things will need to happen as oil runs out: (1) We will need to manufacture polymers from a different feedstock, and (2) we will to need to become much better at reusing and recycling existing polymers.

The manufacture of polymers from crops such as sugarcane is already an important industry and is likely to grow. ${ }^{11,16}$ Elastomers such as rubber made from polyisoprenes derived from trees such as the Hevea brasiliensis in places such as Thailand, Malaysia, and Indonesia now make up 44\% of the global production of rubber, with the rest coming from crude oil. ${ }^{17}$ Could an expansion of these agricultural sources meet the global demand of one billion car tires per year? It is not clear that this will happen, which raises issues regarding the cost and security of the supply. An expansion of the industry is possible, but it would have to compete with other uses for agricultural land that give rise to social justice issues. ${ }^{16}$

If we assume that the use of car and truck tires will reach a steady state by 2050 , then an obvious solution is to recycle used tires to make new ones. However, this materials technology is not economically viable; indeed, there is a growing mountain of used car tires that have no use and are mostly disposed of by incineration. ${ }^{18}$ It seems clear then that by 2050 , we will need to have found a way to make recyclable elastomers for transportation within cities, and indeed between them. This work is a major opportunity for materials scientists and engineers in 2015. Genetic engineering of rubber trees to protect them from disease, to increase yield, and perhaps to make them able to grow in a wide range of climates is a possibility. More generally, collaborations among materials scientists, botanists, biologists, farmers, environmentalists, anthropologists, and governments to pioneer sustainable and socially-just biomaterials seem inevitable.

Such an approach to the use and reuse of a material is called a closed-loop system. ${ }^{11,19-22}$ I focused on polymers as an example of where the materials community needs to move toward a closed loop because the oil feedstock is a finite resource. Although there is no real danger of running out of many of the other materials on which we rely, it is becoming clear that there are a number of other reasons to move toward closed-loop systems. The most important is economic: Reducing waste will save businesses money. ${ }^{19}$

Allwood and Cullen ${ }^{11}$ showed that five materials account for $55 \%$ of carbon dioxide emissions from global manufacturing: steel, cement (for use in concrete), plastic, paper, and aluminum. 
Reducing the $\mathrm{CO}_{2}$ emissions to reduce our risks of catastrophic climate change while allowing for the growth of cities to accommodate 10 billion people is going to be a major challenge. Allwood and Cullen ${ }^{11}$ showed that there is scope for making the manufacturing of these materials more energy-efficient, but only by about $10-20 \%$, which is not enough to keep $\mathrm{CO}_{2}$ emissions down to low-risk levels. Thus, there is a growing consensus in both the business and engineering communities that the most effective strategy for sustainably supporting the growth of cities, and the people and economies they support, is to use steel, concrete, plastic, paper, aluminum, and other materials for longer-indeed, to design all materials systems for reuse, repair, and recycling. . $^{11,19}$

As currently designed, a modern smart phone contains half of the elements of the periodic table and has an average life of three years. Yet, very little of an average smart phone is recycled to produce the new generation of communication devices. Clearly, this will have to change. Even products as simple and as fundamental as a washing machine, a product that could easily last 30 years, now have a decreasing lifespan as we increasingly opt to make and buy products that are designed to fail. . $^{2,24}$

It is likely that the materials engineers in 2050 will spend a lot more of their research efforts understanding the fundamental science and engineering of how to design long-lasting, repairable, reusable, and recyclable materials. The germs of this approach are already evident in the fast growth of research into self-healing materials such as self-healing concrete, ${ }^{25}$ selfhealing electronics, ${ }^{26}$ and self-healing and smart composites. ${ }^{27}$

This increased role of reuse and repair of materials is likely to require a wholesale change in society's relationship with materials. To facilitate repair, people need access to equipment and a community willing to share specialist knowledge. The rise of public workshops, such as hackerspaces and makerspaces, which provide access to advanced manufacturing and robotic tools to local communities, is accelerating the transition to this more "makerly" society, ${ }^{28,29}$ as are the more commercial versions, such as TechShop. ${ }^{30}$ Materials science is represented in these spaces by the increasing provision of materials libraries ${ }^{31}$ and the use of machines such as laser cutters and three-dimensional (3D) printers to modulate and manipulate materials to create new properties, for example, with metamaterials. ${ }^{15}$ In this way, makerspaces are becoming an interesting model for redistributing manufacturing and creating multipurpose factories in the hearts of the cities of the future. ${ }^{32}$

\section{Energy security}

The growing consensus in 2015 that a precautionary principle is needed to deal with the unacceptable risk of climate change means that we will need to reduce the use of fossil fuels quite drastically by 2050 . In their place will be electric energy generated from solar power, wind, and nuclear fission. These are all mature technologies that are being scaled up and further developed now. It is likely that they will also be supplemented by hydrogen power and biofuels. Many materials issues will need to be solved in the move toward a completely renewable energy society.

The primary issue is that of energy storage. Solar energy is plentiful: We need to capture only $1 \%$ of the solar flux to meet all our energy needs. ${ }^{33}$ However, even if we could achieve that level of capture, we would still be faced with the problem of storing that energy during the day so that we could use it at night when there is no sunlight. Existing battery technology, although it meets our current needs for mobile telecommunications, is not up to the job. This is partly because of the volume needed to store that amount of energy, but also because of the losses that storage produces. Therefore, electrical energy storage represents a major materials research effort and is set to continue to be so. Lithium battery technologies have the greatest potential to meet automotive needs for electric vehicles in the short term, ${ }^{34}$ but other technologies based on supercapacitors, perhaps built using 2D materials, nanotubes, and other materials, look promising. ${ }^{35,36}$ Energy storage for the electricity grid requires different characteristics: ${ }^{37}$ Unlike for mobile applications, weight is not an issue; what is more important is power per volume, capacity, and cost. The most efficient current technology is pumped hydroelectric, but this relies on there being a hill or mountain nearby where the energy is being generated. Flow batteries, ${ }^{36,38,39}$ superconducting storage devices, ${ }^{36,39}$ pumped heat, ${ }^{39,40}$ and flywheels ${ }^{39,41}$ all seem promising, and it is likely that a mix of these technologies will be successful.

An alternative way to store energy is through the production of hydrogen, which can then be used to produce electricity using fuel cells. Fuel cells have been in use for specialist applications for decades and have been tested for automotive applications, ${ }^{42}$ for which the main issues are durability and cost. ${ }^{36}$ Japan has rolled out domestic fuel cells to 100,000 homes in an attempt to address cost issues through mass production. ${ }^{43}$ Domestic fuel cells combine heat and electric outputs for the domestic environment and have reported efficiencies approaching $90 \% .^{43}$

Solar cell capacity is growing exponentially, and solar power is anticipated to become the world's largest source of electricity by 2050 , with most being deployed in China and India. ${ }^{44,45}$ Current photovoltaic solar cells based on silicon are not particularly efficient or cheap, but gains in efficiency and cost look to be on the horizon with multijunction, thin-film silicon, as well as other materials systems based on gallium arsenide and cadmium telluride. ${ }^{46}$

Another promising thin-film technology is dye-sensitized solar cells, which have been in use since the 1980s. They have the advantage that they do not require billion-dollar cleanroom facilities, which makes them potentially very inexpensive to make. Their current issues are efficiency and stability. However, their flexibility and ease of manufacture make them a viable contender for 2020 and beyond. ${ }^{47}$

The other notable competitors are perovskite solar cells, which are based on compounds such as methylammonium trihalogen plumbates. Like dye-sensitized solar cells, they are 
easy and inexpensive to make, and they have another advantage in that they do not need a complicated diode architecture to achieve high performance. Efficiencies approaching 20\% have recently been demonstrated, ${ }^{47}$ although the mechanism by which such efficiencies can be achieved is not yet fully understood. ${ }^{48}$ Also, like dye-sensitized solar cells, perovskite solar cells are more suitable for incorporating into roofing materials and glass panels than silicon, so they have the clear potential of being as fundamental to cities in 2050 as steel, concrete, and asphalt.

Buildings of the future are likely to be coated with some sort of solar cell technology. Whichever solar cell technology wins out — perhaps even one not invented yet — one issue that is currently not being seriously addressed is the ability of solar cells to be recycled, repaired, and reused. This will be a very important design parameter if solar cells are to be integrated into the fabric of cities and provide the majority of the world's power in the future. Materials scientists should start thinking about this issue before solar cell materials become a major waste stream.

Wind power is likely to continue to grow, especially in offshore sites. The European Wind Energy Association estimates that in 2030, wind power will provide approximately $14 \%$ of Europe's electricity. ${ }^{49}$ However, wind turbines are expensive to make and maintain, presenting a materials science and engineering challenge. Improvements in the stiffness-to-weight ratio of turbine blade materials are a major requirement. Such improvements would allow longer blades that extract more energy from the wind while decreasing the weight and, thereby, reducing the forces on the structure and minimizing fatigue failures. Carbon-fiber composites are increasingly the materials of choice for wind turbines. However, they are expensive, not particularly damage-tolerant, and difficult to manufacture.

The materials research goal is to address all of these issues, while also allowing designers the freedom to control the microfiber architecture of the reinforcing fibers. A move toward $3 \mathrm{D}$ carbon fiber fabrics so that the triaxial load can be fully optimized in the structure would improve performance, ${ }^{50}$ as would the use of carbon-nanotube-based fibers. ${ }^{51}$ Technologies such as 3D knitting, imported from the fashion world, which can produce $3 \mathrm{D}$ woven structures, can be expected to find their way into the production of these advanced composites. ${ }^{52}$ The ability to add electronic and optical fibers into the weave of a fabric, without compromising structural properties, promises to allow the in situ monitoring of crack propagation and perhaps even the deployment of self-repairing mechanisms. The inclusion of actuators into composites to allow the blades of wind turbines to change their angle to further increase their efficiency is also a possible direction. Offshore wind applications of such self-monitoring, self-repairing, shape-changing composites would be the perfect setting for developing these materials for deployment into other more safety-critical applications such as aerospace.

Nuclear power will be a significant part of the future, providing, as it does, steady and dependable electric energy.
Nevertheless, because of its perceived risks and ongoing legacy of nuclear waste, its development is likely to be driven by political factors. For example, in the wake of the Fukushima disaster of 2011, Germany announced that it was divesting itself of nuclear reactors, whereas its neighbor France, continues to generate $75 \%$ of its electricity from nuclear power. Although it is possible that nuclear power station designs will continue to develop, with efforts to improve the sustainability, economics, safety, reliability, and proliferation-resistance of nuclear installations, the conservatism in the nuclear power industry is likely to make slow progress in that area. Methods to safely encapsulate, store, and monitor nuclear waste, however, are still in their infancy. Low-activity radioactive waste is often stored until it is safe to dispose, whereas the strategy for higher-level radioactive waste is either reprocessing or long-term geological storage. If we are not to leave a major headache to our children in 2050 , it is important that these materials strategies and technologies be further developed. ${ }^{53}$

As far as energy generation is concerned, there is a joker in the pack. If room-temperature superconductors are discovered, then very effective and inexpensive energy storage based on this materials technology would change not just battery technology, but also energy generation, as $100 \%$ efficient transmission of energy would allow the development of a global electricity grid. Avoiding the current high losses in electrical power distribution would mean that energy generation in geographical areas of high solar flux could continuously provide electricity to the rest of the world. At present, high-temperature superconductors still require cryostatic cooling to temperatures on the order of $110 \mathrm{~K}$, which is achievable using liquid nitrogen, but which still makes this technology mostly uneconomical for large-scale transmission of electrical power. ${ }^{54}$ This is an area in which the development of new computer modeling techniques that allow quantum mechanical calculations to be performed over wide ranges of potential compounds could yield breakthroughs. At present, there is no academic consensus as to whether room-temperature superconductivity is actually possible. ${ }^{54}$

\section{Food and water security}

Feeding a world with an estimated population of 9.6 billion people in 2050 is likely to be as much of an engineering challenge as an agricultural one. Although the world produces enough food to feed everyone, famine and starvation are still common problems in parts of the world, and such crises are likely to grow. Materials science and engineering will play a major role in solving such issues through further progress in the manufacturing of effective and environmentally sustainable packaging ${ }^{55}$ and probably also the development of synthetic food, including meat. ${ }^{56}$

One of the major roles of materials engineering is in the packaging of food, without which much food is wasted. Almost all of the food and drink entering households is contained in packaging. This includes the billions of steel and aluminium cans made every year, for which the major materials 
science issue is preventing the food and drinks from reacting with the can. At present, this requires barrier layers based on epoxies, but such materials require much more work. For instance, some of these epoxies include bisphenol A (BPA), an endocrine disruptor that has been shown to cause early puberty, obesity, miscarriages, and increased rates of cancer. ${ }^{57}$ Of course, the dose is all-important in determining whether these negative effects are observed, but in 2004, the US Centers for Disease Control and Prevention found detectable levels of BPA in $93 \%$ of urine samples from people six years and older. ${ }^{57}$ Excluding BPA and other endocrine disruptors from all packaging thus seems to be a sensible precaution, but engineering a replacement material is not so simple..$^{57,58}$

As of 2015, most packaging is based on polymers derived from petrochemicals, and as the latter run out, they are likely to become expensive. Finding replacements will be a major materials science goal. Recycling of packaging seems an obvious route, but there is a fundamental problem: At the scale of individual households, packaging represents a small proportion of the total waste, and for packaging to be recycled effectively, it needs to be separated from organic food waste and other materials. By its very nature, packaging is designed to be low value, representing only a small fraction of the cost of the product; manufacturers thus have little incentive to assume responsibility for its disposal. For the same reason, households themselves have little incentive to recycle packaging. Reducing packaging might seem an obvious route to explore, but there is ample evidence that packaging saves food waste, so reducing it beyond certain levels will be counterproductive. ${ }^{55}$

One of the outcomes of the current situation is the widespread pollution of the oceans by plastic packaging, putting all marine organisms at risk. ${ }^{59}$ Creating sustainable packaging technologies is a major challenge for materials science and engineering. Many options are currently being explored, several of which take a biomimetic approach, such as biodegradable polymers, water-soluble polymers, and natural and semisynthetic polymers. ${ }^{60}$ Intelligent packaging shows great promise, for example to allow intelligent automatic sorting of waste, but also to monitor oxygen, humidity, and freshness levels of food and drink so as to reduce waste. Nanostructured coatings that enhance the barrier properties of packaging films and improve the functionality of biodegradable polymers are likely to be important. ${ }^{61}$

Clean water for drinking, agriculture, washing, and industrial processes is predicted to be an extremely scarce resource by 2050 . Already in $2015,10 \%$ of the world's population does not have access to safe drinking water, and $44 \%$ of the world's population and $28 \%$ of the world's agriculture are in regions of the world where water is scarce. ${ }^{62}$ The Intergovernmental Panel on Climate Change warns of a coming water apocalypse: By 2025, 1.8 billion people are projected to live in areas afflicted by water scarcity. ${ }^{6}$ In addition, climate models predict that as global temperatures increase, extreme droughts are likely to become common across large parts of the world.
Given that $98 \%$ of Earth's water is saline, the ability to purify and desalinate water in an inexpensive, energy-efficient, and locally sustainable manner for water-stressed communities is a major goal for materials science and engineering. New desalination technologies, such as membrane separation techniques based on nanoporous graphene ${ }^{63}$ and graphene oxide, ${ }^{64}$ will need to be developed well before 2050 to prevent famines, mass migration, and economic collapse in many vulnerable countries.

\section{Health care}

Although most babies born in 1900 did not live past age 50, in developed economies in 2015, life expectancy exceeds 80 years. ${ }^{65} \mathrm{~A}$ desire to live longer is a natural one for most, but in the 21 st century, we are seeing a greater demand not only for increased lifespans but, more importantly, for higher quality of life during old age. This translates into the desire to live healthier independent lives for longer. Materials science and engineering is one of the key disciplines required to respond to this goal, and several new technologies are converging to create new possibilities for 2050 .

Historically, the function of biomaterials has been to replace diseased or damaged tissues. As such, biomaterials were selected to be as inert as possible while fulfilling mechanical roles such as tooth fillings, dentures, and hip replacements. These implants have been remarkably successful. In 2015, over 300,000 hip replacements will be performed worldwide, two-thirds in patients over 65 years of age. Ninety percent of patients can expect to have their total hip replacements functioning at 10 years, and in $85 \%$ of patients, the replacements will still be functioning at 20 years. ${ }^{66}$ Other parts of the body will likely give out within this time frame, such as knees and other joints. Thanks to developments in tissue engineering, there is the potential for both hard and soft tissues to be grown to order for patients. Much of this work is based on scaffold technology, in which a tissue scaffold is designed with specific chemical properties and microporous structures. ${ }^{67,68}$ Stem cells from the patient are then supported to grow into these scaffolds using bioreactors, resulting in cell differentiation into bone, cartilage, or soft tissue, as required. ${ }^{67,68}$ Bioglass was the first scaffold material invented. Pioneered by Larry Hench to regrow bone, it has been in clinical use for many years. ${ }^{69}$ The world's first synthetic tracheal replacement, using a novel nanocomposite scaffold employing the patient's own cells, was grown and implanted in 2011 with a successful outcome. ${ }^{70}$ No one yet can put limits on how far this scaffold-based tissue engineering technology can go. Whether it will be capable in 2050 of producing new functioning organs such as the liver, the kidney, and even the heart is an open question. ${ }^{70,71}$

Nanotechnology is providing a promising approach to develop therapies for diseases such as cancer in which madeto-order drugs are targeted using fluorescent quantum dots and plasmonic gold nanoparticles. ${ }^{72}$ The technology to modify the surface of nanoparticles and to deliver them to certain sites in the body is well advanced. ${ }^{73}$ 
Another trend for extending mobility and fighting the diseases of old age is augmentation. This could be in the form of increasingly sophisticated and affordable exoskeletons to help monitors health and delivers medicine; or electronic implants that augment vision, memory, or other human faculties. The hearing aid has been one of the most successful products in this respect. By 2013, more than 10 million 3D-printed hearing aids were in use. ${ }^{74}$ Indeed, 3D printing of other augmentation technologies is likely to be a major objective, and this will require a much better fundamental understanding and development of additive manufacturing technologies. ${ }^{75,76}$ Printing of made-to-order devices, implants, and prosthetics in hospitals, such as 3D-printed jawbones, is already happening ${ }^{76}$ and will change medicine quite radically by $2050 . .^{77,78}$

There is an ongoing convergence among medicine, biology, and materials science, and ensuring that collaborations work effectively will be the key to progress. Yet, this is not straightforward, as a fundamental change in what research is carried out and for whom is likely to be needed if the full potential of biomaterials is to be realized. ${ }^{28,71}$

\section{Materials development methodologies}

Designers, architects, medics, engineers, and everyone else who makes things are faced with an increasingly wild "jungle of choices" when it comes to selecting a material. ${ }^{79} \mathrm{In}$ the aged and infirm get around (see Figure 2); clothing that

1997, science writer Philip Ball (a contributor to this issue) estimated that there were between 40,000 and 80,000 distinct materials to choose from when fabricating an artifact. ${ }^{79}$ In 2005, materials engineer Mike Ashby estimated the number to have grown to $120,000,{ }^{80}$ and current estimates put the number at $160,000 .^{81}$

Equally, materials producers are faced with a saturated marketplace in which their materials jostle for attention and have to compete for market share. The materials requirements of designers are often not relayed back to materials researchers, and, as a result, many materials fail to find a niche in a competitive marketplace. ${ }^{82}$ Because of increasing disciplinary specialization, materials researchers tend to have expertise in a narrow range of technologies and processes. It is thus becoming increasingly difficult for designers, engineers, academics, and even organizations to have in-depth knowledge across the entire spectrum of materials.

Traditionally, approaches to materials selection and development were experimental and therefore slow. ${ }^{8}$ Much progress has been made, but it still takes decades to optimize suitable materials for a technological application. ${ }^{80} \mathrm{~A}$ principal reason for this long discovery process is that materials design is a complex, multidimensional optimization problem, and the data needed to make informed choices usually do not exist. ${ }^{83}$ Theory blossomed in the 20th century, but its actual use in the invention of new materials in 2015 is still limited. Indeed, this issue was identified by the US federal government's Materials Genome Initiative: ${ }^{4}$

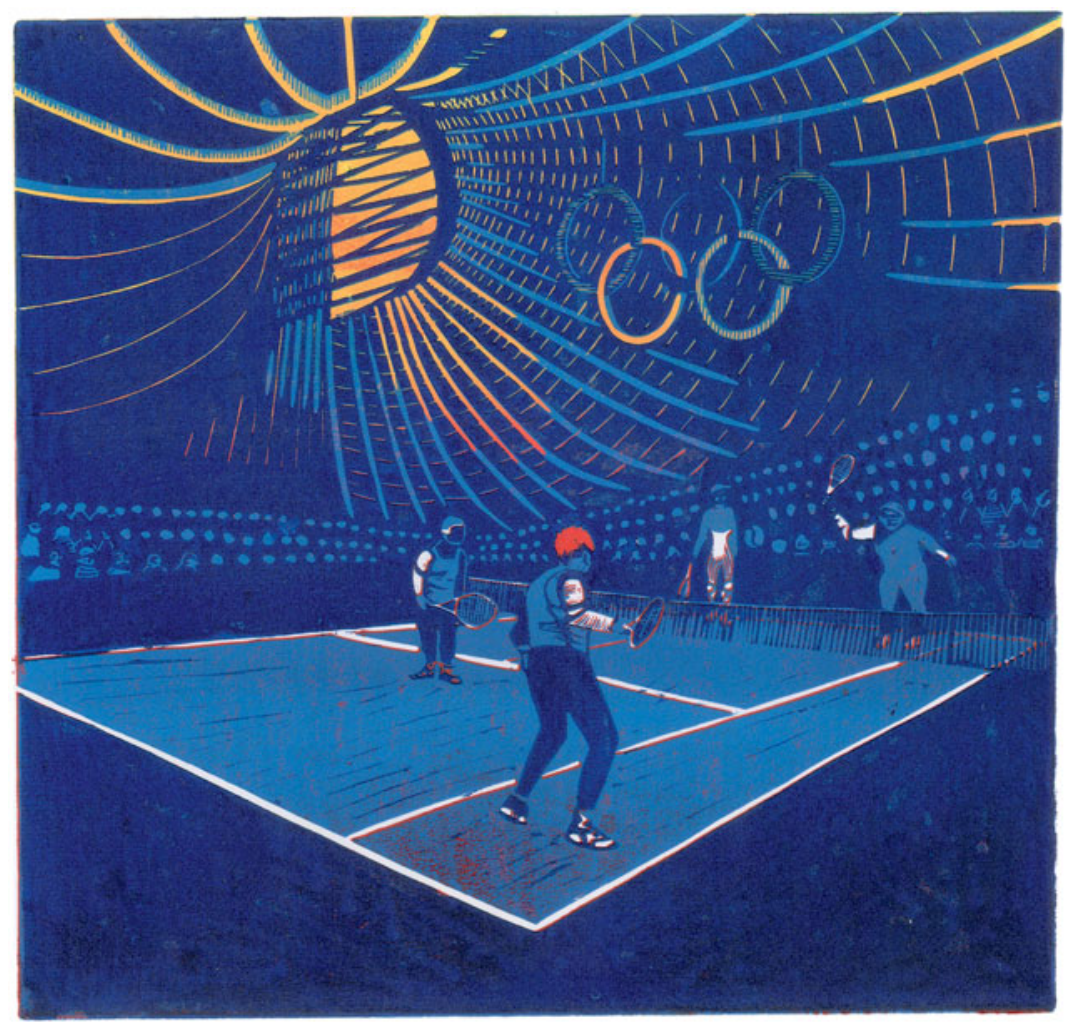

Figure 2. One of our possible futures: where centenarians compete in a world tennis tournament.
The primary problem is that current predictive algorithms do not have the ability to model behavior and properties across multiple spatial and temporal scales; for example, researchers can measure the atomic vibrations of a material in picoseconds, but from that information they cannot predict how the material will wear down over the course of years.

The Materials Genome Initiative Strategic Plan identifies four main goals: (1) leading a culture shift in materials science research to encourage and facilitate an integrated team approach; (2) integrating experiment, computation, and theory and equipping the materials community with advanced tools and techniques; (3) making digital data accessible; and (4) creating a world-class materials science and engineering workforce that is trained for careers in academia or industry.

This change in methodology from a fragmented, experimentally based approach to a more integrated, theory- and data-led approach sounds appealing and has yielded some notable successes. ${ }^{84}$ This call for a culture shift in 
materials research methods is echoed elsewhere. ${ }^{71,85}$ It is something that I have also been championing, but with a slightly different perspective, ${ }^{31,79}$ namely, that there has been an increased specialization of materials practitioners, to the point where the scientists, technologists, and industrialists (i.e., the materials science community) involved in the development of new materials now move in both academic and social circles widely separated from those of industrial designers, architects, clothes makers, and medical experts.

Take the example of the development of new wound dressings, which are crucial for treating many chronic diseases. The first issue is that this sort of problem does not fit into the realm of classical materials science and engineering activities, so it tends to be ignored. The functionality of wound dressings is distributed across many scales, from the nanoscale of their antibacterial function, to the microscale of the membrane layers controlling humidity, to the mesoscale of their fluid-handling properties, to the macroscale of their form-fitting attachment to the body. Moreover, aesthetic properties, such as smell and color, are important and can dramatically affect how patients feel about their treatment and condition; this affects recovery rates, which then has a huge effect on both the costs incurred by hospitals and the patients' well-being. Thus, developing new wound healing systems not only involves solving physical and biological problems, as well as issues of disposal and recycling, but also requires an understanding of the look and feel of materials and their context in a healthcare or domestic setting. ${ }^{86}$ As our materials needs in every area of our lives grow more sophisticated, the solutions also become more complex.

The second issue is that, although useful, theory cannot take the lead in an approach to a problem that involves human behavior - because adequate theories of human behavior are not available. Instead, we need to ask those who use the wound dressings, who administer them, and who make them what works. We also need to build prototypes and test prototypes with patients and nurses to incorporate feedback into the fundamental materials design. This is true not just for medical devices, but for all materials applications involving humans. Although this might sound like the exact opposite of the Materials Genome Initiative approach, I do not think it is, although it emphasizes the iterative nature of materials design and the importance of human insight and knowledge of the material stuff of the world - theory and data are useful only in that context. As materials scientist Cyril Stanley Smith commented:

The great success of the logical analytical reductionist approach to understanding over the last four centuries and the utility of the application of its principles has not negated the evidence of history that the sensualemotional-aesthetic capabilities of the human being also have validity. The problem is to find the proper nonexclusive role for each. ${ }^{87}$

Materials are fundamentally multiscale, and this is why there is as much to be learned about materials design through the production and trial of full-scale prototypes as through the application of theory. To assemble multidisciplinary teams with experts in each scale requires laboratories that facilitate analysis, microscopy, and equipment to build and test physical prototypes. This will be a significant switch for materials scientists, who often hand over a material technology to engineers and designers and consider their work to be done.

Materials libraries have a significant part to play too, because they are essentially physical catalogues of potential materials solutions. ${ }^{31}$ This approach to materials design relies on practical materials knowledge, not because theory is irrelevant to tackling complex problems, but because making stuff such as bandages, exoskeletons, or solar roof tiles means that materials scientists and engineers need to better understand the design factors that are important at the human scale. This theme is the reason behind the increasing popularity of FabLabs and makerspaces..$^{29,30,88,89}$

There is much at stake, because materials have an immense cultural and environmental significance, and the introduction of new materials by an isolated materials science community holds the prospect of a further deepening of the rift between scientists and society. Some combination of this practical approach and the materials genome approach is likely to be the hallmark of materials development laboratories in $2050{ }^{89}$

\section{Material dreams}

\section{"What you think is the point is not the point at all but only the beginning of the sharpness."}

\section{_Flann O'Brien, The Third Policeman}

The role of the imagination in determining the direction of human technology should not be underestimated. Authors, artists, architects, and filmmakers all envision futures that influence the direction of materials research. They do this by influencing the imaginations of materials scientists and engineers. The invisibility shields that H.G. Wells wrote about are now becoming a reality through the development of metamatierals, ${ }^{15}$ Star Trek's replicators are manifested in 3D printers, ${ }^{32}$ the self-cleaning materials from the 1951 film The Man in the White Suit are here today. All of these once-fanciful applications are now reality, and so are the social and economic implications that come along with them: ${ }^{2}$ It is not impossible that the replicants from the film Blade Runner will yet find their way into our lives. By 2050, our world might feel like a dystopian novel by J.G. Ballard or a more optimistic film like Back to the Future II, and the outcome depends, to some extent, on those who want to transform those types of fiction into existence.

We have the knowledge to do this. Nanotechnology is one of the fastest growing areas of research in materials science. The number of possibilities is limitless, but what is more interesting is that many of the structures at this scale self-assemble. This means that the materials are able to organize themselves using electrostatic and surface tension forces (and heal 
themselves in the same way). The development of nanostructures to collect sunlight to produce a new generation of solar cells that are self-assembling and self-healing is one example.

At the microscale, materials science is starting to design structures that are able to control light. These metamaterials can be formed with variable refractive indices, which means that they can bend light in any desired direction. ${ }^{15}$ This has yielded the first, primitive generation of invisibility shields, which, when surrounding an object, bend light around it so that, from whichever direction you try to observe the object, it appears to vanish. ${ }^{90}$ These metamaterials might also make possible a new generation of optical computers that use light and not electrons - and make existing computers look very slow and power hungry, especially if the new computers use quantum logic.

Although designing structures at different scales provides the possibility of extraordinary smart materials, the real challenge is linking up the scales of such structures into a macroscopic human-sized object. ${ }^{91}$ Smart phones are an example of the integration of a touch-sensitive screen and clever electronics. The idea that whole objects might be so wired, like an electronic nerve system, and thus sensitive to touch, is now becoming possible through plastic electronics. Indeed, by 2050, whole rooms, buildings, and even bridges might generate their own energy, funnel it to where it is needed, detect damage, and self-heal. If this seems like science fiction, it is what living materials already do. ${ }^{5}$

Thermochromic materials started to emerge from the laboratory in the $1960 \mathrm{~s}$, about the same time as the first digital watches, and were based on the same display technologies, liquid crystals. Although they have fared less well in development than liquid-crystal displays, their time might be about to come. Houses of the future, and especially roofs, could be engineered to change color to white when they are hot to reflect more sunlight and require less air conditioning. Thermochromic switchable glass already has this capability for windows that are designed to be spectrally selective, affecting only the infrared transparency, letting heat through in the winter to take advantage of passive solar heating and blocking it in the summer. Given that $40 \%$ of the energy consumption of developed economies is spent in the heating and cooling of buildings, such coatings could certainly be useful. But also the idea that whole buildings, streets, and even cities might change color throughout the seasons is surely an architecturally thrilling one. Indeed, buildings and cities that are more responsive to climate will surely be a reality brought about by advances in materials engineering by 2050 .

Whatever people think about the rapid pace of change in the past, the fundamental arrangement of materials on the planet has not changed. There are living things that we call life, and there are nonliving things that we call rocks, tools, buildings, and so on. As a result of our greater understanding of matter, this distinction is likely to become blurred. By 2050, bionic people, augmented with synthetic organs, bones, and even brains, could become normal. Just as we become more synthetic, so our engineered environment might change to become more lifelike, with living buildings and self-healing bridges. Perhaps, we will succeed in developing wearable exoskeleton underwear that will allow us to live and play tennis even when we are 100 years of age. ${ }^{92}$

Whatever happens, it seems certain that humanity's love affair with stuff is not going to end any time soon. Materials are, quite literally, a physical reflection of who we are, and as long as we are changing, so will our material world. The day we stop evolving will be the day we stop inventing new materials.

\section{Acknowledgments}

The author thanks all members of the UCL Institute of Making, past and present; Alun Carr, Bat Baptiste, Ian Hamerton, and Adrian Smith for useful discussions; and Ruby Wright for inspiration and the illustrations.

\section{References}

1. A. Macfarlane, G. Martin, The Glass Bathyscaphe: How Glass Changed the World (Profile Books, London, 2002).

2. M. Miodownik, Stuff Matters (Penguin Books, London, 2013).

3. P. Purnell, Adv. Cem. Res. 25 (6), 362 (2013).

4. "Materials Genome Initiative Strategic Plan" (National Science and Technology Council, Washington, DC, 2014), available at http://www.whitehouse.gov/sites/ default/files/microsites/ostp/NSTC/mgi_strategic_plan_-_dec_2014.pdf (accessed June 2015).

5. M. Pawlyn, Biomimicry in Architecture (RIBA Publishing, London, 2011).

6. "Climate Change 2014 Synthesis Report" (IPCC, Geneva, Switzerland, 2014), available at http://www.ipcc.ch/pdf/assessment-report/ar5/syr/SYR_AR5_FINAL_ full.pdf (accessed June 2015).

7. "World Urbanization Prospects, the 2014 revision" (Population Division, Department of Economic and Social Affairs, United Nations, New York, 2014), available at http://esa.un.org/unpd/wup (accessed March 2015).

8. M.F. Ashby, Materials and the Environment (Butterworth-Heinemann, Oxford, UK, 2009).

9. T.E. Graedel, L. Erdmann, MRS Bull. 37 (4), 325 (2012).

10. T.E. Graedel, E.M. Harper, N.T. Nassar, B.K. Reck, Proc. Natl. Acad. Sci. U.S.A. 112 (20), 6295 (2013).

11. J.M. Allwood, J.M. Cullen, Sustainable Materials: With Both Eyes Open (UIT Cambridge, Cambridge, UK, 2012).

12. C.-W. Yap, "China Ends Rare-Earth Minerals Export Quotas," Wall Street Journal (January 5, 2015), available at http://www.wsj.com/articles/china-endsrare-earth-minerals-export-quotas-1420441285 (accessed March 2015).

13. "Strategic and Critical Materials 2013 Report on Stockpile Requirements" (US Department of Defense, Washington, DC, 2013).

14. "Directive 2011/65/EC of the European Parliament and of the Council of 8 June 2011 on the Restriction of the Use of Certain Hazardous Substances in Electrical and Electronic Equipment (recast)" (European Parliament, Brussels, Belgium, 2011), available at http://eur-lex.europa.eu/legal-content/EN/TXT/?qid= 1399998664957\&uri=CELEX:02011L0065-20140129 (accessed June 2015).

15. Y. Liu, X. Zhang, Chem. Soc. Rev. 40, 2494 (2011).

16. M.D. Tabone, J.J. Cregg, E.J. Beckman, A.E. Landis, Environ. Sci. Technol. 44 (21), 8264 (2010).

17. International Rubber Study Group, http://www.rubberstudy.com (accessed March 2015)

18. M. Myhre, D.A. MacKillop, A. Duncan, Rubber Chem. Technol. 75 (3), 429 (2002).

19. "Towards the Circular Economy" (Ellen MacArthur Foundation, Cowes, UK, 2012), vol. 1, available at http://www.ellenmacarthurfoundation.org/business/ reports (accessed June 2015).

20. M. Braungart, W. McDonough, Cradle to Cradle: Remaking the Way We Make Things (North Point Press, New York, 2002).

21. T.E. Graedel, B.R. Allenby, Industrial Ecology, 2nd ed. (Pearson Education, Upper Saddle River, NJ, 2003).

22. S.E. Wilkes, "In Search of Sustainable Materials: Negotiating Materiality and Morality in the UK Materials Industry," PhD thesis, University College London (2014).

23. C.A. Bakker, M.C. den Hollander, E. van Hinte, Y. Zijlstra, Products That Last: Product Design for Circular Business Models (TU Delft Library, Delft, The Netherlands, 2014). 
24. Right to Repair, http://www.digitalrighttorepair.org (accessed March 2015). 25. V. Wiktor, H.M. Jonkers, Cem. Concr. Compos. 33 (7), 763 (2011).

26. B.J. Blaiszik, A.R. Jones, N.R. Sottos, S.R. White, J. Microencapsul. 31, 350 (2014)

27. R.S. Trask, C.J. Norris, I.P. Bond, J. Intell. Mater. Syst. Struct. 25, 87 (2014). 28. M. Miodownik, Mater. Today 16 (12), 458 (2013).

29. Fab Foundation, http://www.fabfoundation.org/fab-labs (accessed June 2015). 30. TechShop, http://www.techshop.ws (accessed June 2015).

31. M.A. Miodownik, Pure Appl. Chem. 79, 1635 (2007).

32. C. Anderson, Makers: The New Industrial Revolution (Crown Business, New York, 2014)

33. N.S. Lewis, "Basic Energy Needs for Solar Energy Utilization" (Office of Science, US Department of Energy, Washington, DC, 2005), available at http:// science.energy.gov/ /media/bes/pdf/reports/files/seu_rpt.pdf (accessed June 2015)

34. M. Balaish, A. Kraytsberg, Y. Ein-Eli, Phys. Chem. Chem. Phys. 16, 2801 (2014). 35. G. Wang, L. Zhang, J. Zhang, Chem. Soc. Rev. 41 (2), 797 (2012).

36. C. Liu, F. Li, L.-P. Ma, H.-M. Cheng, Adv. Mater. 22, E28 (2010).

37. D.J.C. MacKay, Sustainable Energy - Without the Hot Air (UIT Cambridge, Cambridge, UK, 2009), available at http://www.inference.eng.cam.ac.uk/sustainable/ book/tex/sewtha.pdf (accessed June 2015).

38. B.R. Chalamala, T. Soundappan, G.R. Fisher, M.R. Anstey, V.V. Viswanathan, M.L. Perry, Proc. IEEE 102 (6), 976 (2014).

39. X. Luo, J. Wang, M. Dooner, J. Clarke, Appl. Energy 137, 511 (2015).

40. A. Thes, Phys. Rev. Lett. 111, 110602 (2013).

41. C. Nelder, "Turn Up the Juice: New Flywheel Raises Hopes for Energy Storage Breakthrough," Scientific American (April 10, 2013).

42. "The Fuel Cell Industry Review 2014" (E4tech, London, 2014), available at http://www.fuelcells.org/pdfs/TheFuelCellIndustryReview2014.pdf (accessed June 2015).

43. Tokyo Gas, "Development of the New Model of a Residential Fuel Cell, 'ENE-FARM'," available at http://www.tokyo-gas.co.jp/techno/english/menu3/2 index_detail.html (accessed June 2015).

44. European Photovoltaic Industry Association, "Global Market Outlook for Photovoltaics 2014-2018," available at http://www.epia.org/news/publications/ global-market-outlook-for-photovoltaics-2014-2018 (accessed June 2015).

45. X.-G. Zhao, G. Wan, Y. Yang, Renew. Sustain. Energy Rev. 41, 178 (2015).

46. M. Konagai, Jpn. J. Appl. Phys. 50, 030001 (2011).

47. M. Eleni, T. Torres, Chem. Commun. 51, 3957 (2015).

48. H.S. Jung, N.-G. Park, Small 11 (1), 10 (2015).

49. G. Failla, F. Arena, Philos. Trans. R. Soc. Lond. A 373 (2035), 20140228 (2015)

50. M. McGugan, G. Pereira, B.F. Sørensen, H. Toftegaard, K. Branner, Philos. Trans. R. Soc. Lond. A 373 (2035), 20140077 (2015)

51. P.-C. Ma, Y. Zhang, Renew. Sustain. Energy Rev. 30, 651 (2014).

52. A.R. Labanieh, X. Legrand, V. Koncar, D. Soulat, J. Compos. Mater. 48 (26), 3243 (2014).

53. 0. Farid, K. Shih, W.E. Lee, H. Yamana, in Radioactive Waste Management and Contaminated Site Clean-Up: Processes, Technologies and International Experience, W.E. Lee, M.I. Ojovan, C. Jantzen, Eds. (Woodhead Publishing, Cambridge, UK, 2013), part II, chap. 24, pp. 744-777.

54. K. Sato, S. Kobayashi, T. Nakashima, Jpn. J. Appl. Phys. 51, 010006 (2012). 55. "Consumer Attitudes to Food Waste and Food Packaging" (WRAP, Banbury, UK, 2013), available at http://www.wrap.org.uk/sites/files/wrap/Report - Consumer attitudes to food waste and packaging_0.pdf (accessed March 2015).

56. H.L. Tuomisto, M. Joost Teixeira de Mattos, Environ. Sci. Technol. 45 (14), 6117 (2011).

57. National Institute of Environmental Health Services, "Bisphenol A (BPA)," available at http://www.niehs.nih.gov/health/topics/agents/sya-bpa (accessed March 2015).
58. R.C. Thompson, C.J. Moore, F.S. vom Saal, S.H. Swan, Philos. Trans. R. Soc. Lond. B 364, 2153 (2009).

59. J.A.I. do Sul, M.F. Costa, Environ. Pollut. 185, 352 (2014).

60. E. Chiellini, R. Solaro, Adv. Mater. 8 (4), 305 (1996).

61. S.D.F. Mihindukulasuriya, L.-T. Lim, Trends Food Sci. Technol. 40 (2), 149 (2014).

62. "Water Scarcity and Desertification," (UNCCD, Bonn, Germany, 2009), available at http://www.unccd.int/Lists/SiteDocumentLibrary/Publications/Desertificationandwater.pdf (accessed March 2015).

63. D. Cohen-Tanugi, J.C. Grossman, Nano Lett. 12 (7), 3602 (2012).

64. R.K. Joshi, P. Carbone, F.C. Wang, V.G. Kravets, Y. Su, I.V. Grigorieva, H.A. Wu, A.K. Geim, R.R. Nair, Science 343, 752 (2014).

65. "Global Health and Aging" (NIH, Washington, DC, 2011), http://www.nia. nih.gov/sites/default/files/global_health_and_aging.pdf (accessed March 2015). 66. K. Schulte, J. Callaghan, S. Kelley, R. Johnston, J. Bone Joint Surg. Am. 75A, 961 (1993).

67. R.H. Harrison, J.-P. St.-Pierre, M.M. Stevens, Tissue Eng. B 20, 1 (2014).

68. M.B. Fisher, R.L. Mauck, Tissue Eng. B 19, 1 (2013).

69. L.L. Hench, J. Mater. Sci. Mater. Med. 17, 967 (2006)

70. C. Crowley, M. Birchall, A.M. Seifalian, J. Tissue Eng. Regener. Med. 9, 357 (2014).

71. G.N. Duda, D.W. Grainger, M.L. Frisk, L. Bruckner-Tuderman, A. Carr, U. Dirnagl, K.M. Einhäupl, S. Gottschalk, E. Gruskin, C. Huber, C.H. June, D.J. Mooney, E.Th. Rietschel, G. Schütte, W. Seeger, M.M. Stevens, R. Urban, A. Veldman, G. Wess, H.-D. Volk, Sci. Transl. Med. 6 , 264cm12 (2014).

72. C.M. Tyrakowski, P.T. Snee, Phys. Chem. Chem. Phys. 16, 837 (2014).

73. P.D. Howes, R. Chandrawati, M.M. Stevens, Science 346, 53 (2014).

74. R. Hague, P. Reeves, Ingenia 55, 39 (2013).

75. B. Derby, Science 338, 921 (2012)

76. S.V. Murphy, A. Atala, Nat. Biotechnol. 32, 773 (2014).

77. C.L. Ventola, Pharmacol. Ther. 39 (10), 704 (2014).

78. F. Rengier, A. Mehndiratta, H. von Tengg-Kobligk, C.M. Zechmann, R. Unterhinninghofen, H.-U. Kauczor, F.L. Giesel, Int. J. Comput. Assisted Radiol. Surg. 5, 335 (2010).

79. P. Ball, Made to Measure: New Materials for the 21st Century (Princeton University Press, Princeton, NJ, 1997)

80. M. Ashby, Materials Selection in Mechanical Design, 3rd ed. (ButterworthHeinemann, Oxford, UK, 2005).

81. M. Ashby, H. Shercliff, D. Cebon, Materials: Engineering, Science, Processing and Design, 3rd ed. (Butterworth-Heinemann, Oxford, UK, 2014).

82. E. Maine, D. Probert, M. Ashby, Technovation 25, 15 (2004).

83. A. Jain, S. Ping Ong, G. Hautier, W. Chen, W.D. Richards, S. Dacek, S. Cholia, D. Gunter, D. Skinner, G. Ceder, K.A. Persson, APL Mater. 1, 011002 (2013).

84. G.B. Olson, C.J. Kuehmann, Scr. Mater. 70 (1), 25 (2014).

85. G.K. Ulrike, H. Bai, E. Saiz, A.P. Tomsia, R.O. Ritchie, Nat. Mater. 14, 23 (2014).

86. C.S Smith, A Search for Structure: Selected Essays on Science, Art, and History (MIT Press, Cambridge, MA, 1981).

87. M. Miodownik, in Materials Transformations: Anthropological Accounts of Materials and Society, S. Küchler, A. Drazin, Eds. (Bloomsbury, London) (forthcoming).

88. "List of Hacker Spaces," http://hackerspaces.org/wiki/List_of_Hacker_Spaces (accessed March 2015).

89. "First Year Report, Institute of Making, UCL, 2013-14" (UCL, London, 2014), available at http://www.instituteofmaking.org.uk/assets/_files/uploads/Instituteof-Making_first-year-report-2014.pdf (accessed June 2015).

90. O. Hess, J.B. Pendry, S.A. Maier, R.F. Oulton, J.M. Hamm, K.L. Tsakmakidis, Nat. Mater. 11, 573 (2012).

91. B. Florijn, C. Coulais, M. van Hecke, Phys. Rev. Lett. 113, 175503 (2014). 92. G. Whitesides, Angew. Chem. Int. Ed. 54, 3196 (2015).

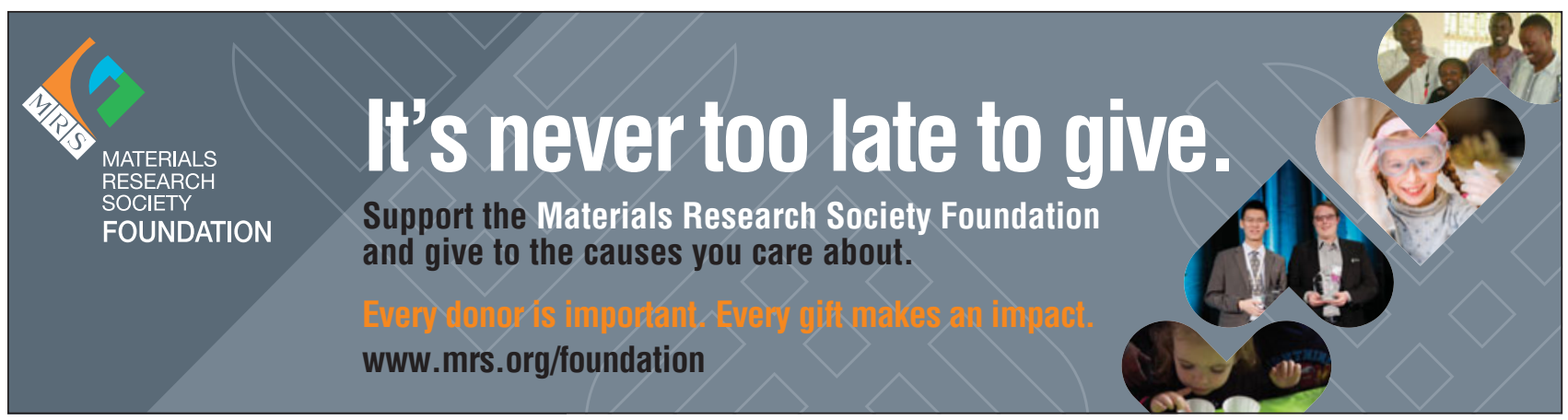




\section{MRS ENERGY Q}

\section{SUSTAINABILITY}

\section{A Review Journal}

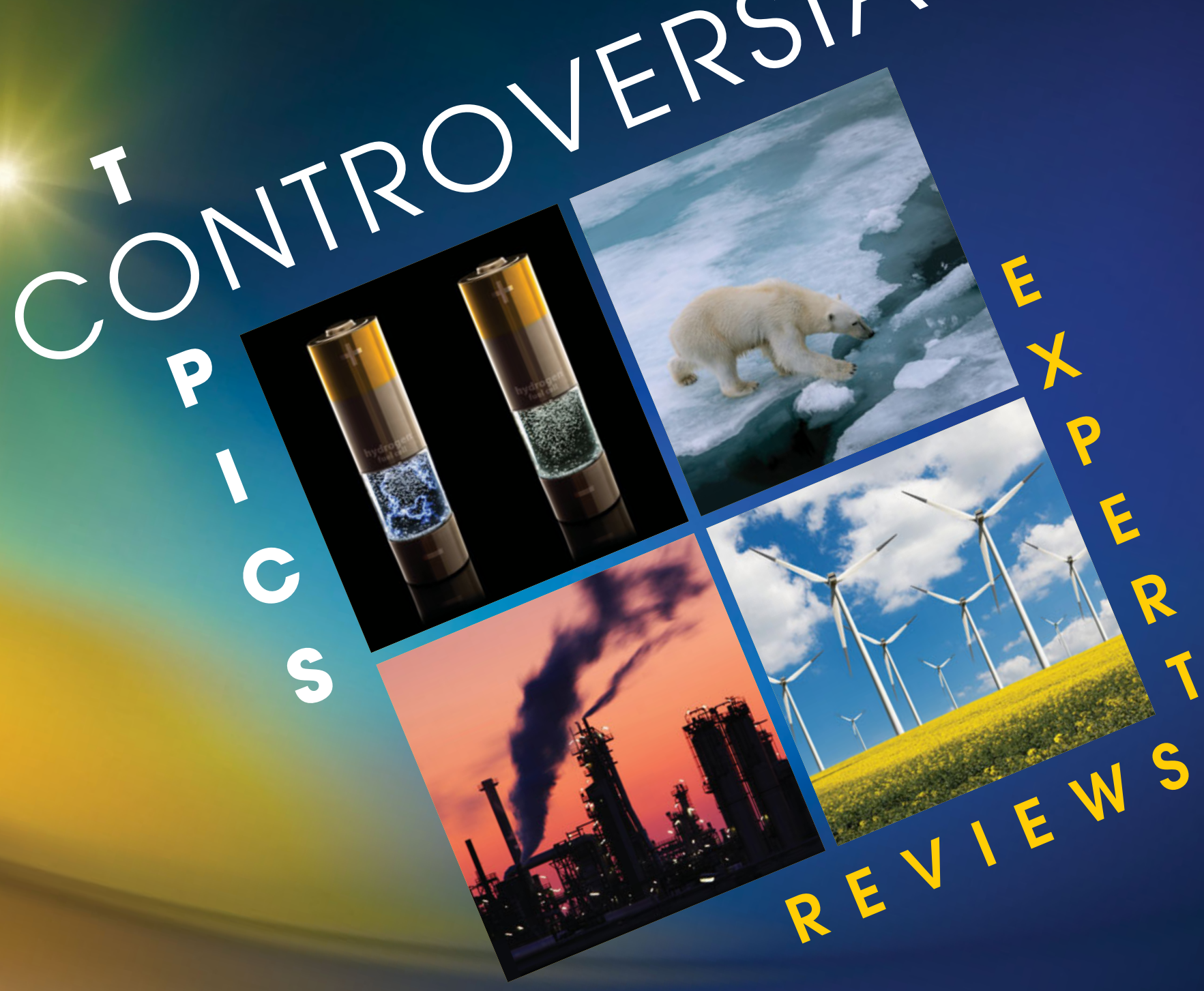

MRS Energy \& Sustainability -A Review Journal publishes reviews on key topics in materials research and development as they relate to energy and sustainability. Review topics include new R\&D of both established and new areas; systems integration; and objective application of economic, sociological and governmental models, enabling research and technological developments. The reviews are set in an integrated context of scientific, technological and sociological complexities relating to environment and sustainability.
는 David S. Ginley

National Renewable Energy Laboratory, USA

O

$z$ David Cahen

के Weizmann Institute of Science, Israel

능

E Elizabeth A. Kócs

University of Illinois at Chicago, USA 